\title{
HARAPAN MASYARAKAT TERHADAP PERAN ANGGOTA LEGISLATIF PEREMPUAN (ALP) DALAM MENDORONG PEMBANGUNAN YANG BERPIHAK PADA PEREMPUAN DAN KEMISKINAN DI POLMAN
}

\author{
Syamsu Alam*
}

\begin{abstract}
This research is based on the idea that women's representation is the support of society, especially women, to fulfill basic rights and basic rights so that problems related to poverty and other problems of gender inequality can be overcome through the voice of women of parliament. This research uses qualitative approach with descriptive type. The location of the research and the determination of informants was chosen purposively by considering the focus on women. Those selected are those directly involved in the management of development at the village / kelurahan level. The result of the research shows that the general knowledge about the Profile of Women Legislative Members (ALP) in Polman Regency is not satisfactory, their knowledge about ALP profile is not deep because most of them do not know well about other data related to ALP like position and party as well the area of the electoral district of the ALP. This is because the ALP is rarely in direct contact with the community and the media is not utilized. Public expectations of a gender-responsive Development Program Arrangement and ensuring the alignment of Women and the Poor are; The ALP should play an active role in promoting village development programs that must be guarded by involving women and the poor to all stakeholders. The ALP should also encourage existing Regulations / Regulations related to Musrembang Village / Sub District / Regency that ensure the representation of Women, and other Marginal Groups.
\end{abstract}

Keywords: Members of the Women's Legislature (ALP), Women and Poverty

\section{PENDAHULUAN}

Pemilihan Umum di Indonesia telah mengalami beberapa perubahan dari periode Pemilu ke periode Pemilu yang lain. Keterlibatan perempuan dalam

*) Prodi PPKn, Universitas Al Asyariah Mandar

E-mail: syamsualam39@yahoo.com 
politik dari waktu ke waktu terus mengalami peningkatan. Salah satu indikatornya adalah trend peningkatan keterwakilan perempuan di legislatif terutama sejak pemilihan umum tahun1999, lalu 2009 hingga pada tahun 2014. Pada Pemilu 1999 (9\%), Pemilu 2004 (11,8\%), dan Pemilu 2009 (18\%).

Peningkatan keterwakilan perempuan terjadi setelah berlakunya perubahan Undaang-Undang Dasar (UUD) Negara Republik Indonesia Tahun 1945 yaitu pasal $28 \mathrm{H}$ ayat (2) yang menyatakan "Setiap orang berhak mendapatkan kemudahan dan perlakuan khusus untuk memperoleh kesempatan dan manfaat yang sama guna mencapai persamaan dan keadilan". Ketentuan UUD 1945 tersebut menjadi landasan yang kuat bagi semua golongan warga negara untuk bebas dari diskriminasi sistematik dan struktural dalam berbagai aspek kehidupan, termasuk pada aspek politik.Karena itu, UU paket politik yang digunakan sebagai landasan pelaksanaan Pemilu 2004, 2009 maupun Pemilu 2014 mengakomodasi norma-norma hukum yang bertujuan untuk meningkatkan keterwakilan perempuan di legislatif. Kebijakan afirmasi (affirmative action )terhadap perempuan dalam bidang politik setelah berlakunya perubahan UUD 1945 dimulai dengan disahkannya UU Nomor 12 Tahun 2003 tentang Pemilu DPR, DPD, dan DPRD.

Peningkatan keterwakilan perempuan berusaha dilakukan dengan cara memberikan ketentuan agar partai politik peserta Pemilu memperhatikan keterwakilan perempuan sekurang-kurangnya $30 \%$ didalam mengajukan calon anggota DPR, DPD, dan DPRD. Pasal 65 ayat (1)UU Nomor 12 Tahun 2003 tentang Pemilu DPR, DPD, dan DPRD menyatakan: "Setiap Partai Politik Peserta Pemilu dapat mengajukan calon Anggota DPR, DPRD Provinsi, dan DPRD Kabupaten/Kota untuk setiap Daerah Pemilihan dengan memperhatikan keterwakilan perempuan sekurang-kurangnya $30 \%$.

Dari waktu ke waktu, affirmative action terhadap perempuan dalam bidang politik semakin disempurnakan. Hal itu dapat ditelaah ketika DPR menyusun RUU Paket Politik yang digunakan dalam pelaksanaan Pemilu 2009, yaitu UU No. 22 Tahun 2007 tentang Penyelenggara Pemilu, UU No. 2 Tahun 2008 tentang Partai Politik dan UU No. 10 Tahun 2008 tentangPemilu DPR, DPD, dan DPRD.UU No. 22 Tahun 2007 tentang Penyelenggara Pemilu mengatur agar komposisi penyelenggara Pemilu memperhatikan keterwakilan perempuan minimal $30 \%$. Pasal 6 ayat (5) UU tersebut menyatakan bahwa :"Komposisi keanggotaan KPU, KPU Provinsi, dan KPU Kabupaten/Kotamemperhatikan keterwakilan perempuan sekurang-kurangnya $30 \%$ (tigapuluh perseratus).Terbaru adalah Undang-Undang No.7 Tahun 2017 
tentang Pemilihan Umum yang mengatur keterwakilan perempuan sedikitnya 30 persen disetiap daerah pemilihan.

Meski demikian, perlu kita ketahui bahwa peningkatan kuota perempuan memang terus terjadi namun tidak terlalu signifikan. Pada pemaparan diatas sudah dikatakan 30\% merupakan kuota perempuan yang harus bisa dipenuhi. Ketentuan kuota ini tidak hanya diperuntuhkan pada DPR RI dan DPD, juga terhadap DPRD Provinsi dan DPRD Kabupaten. Namun pada kenyataannya, pemilu legislatif di Kabupaten Pol-Man pada tahun 2009 hanya mencakup 15\% dari 40 anggota legislatif dan di tahun 2014 mencakup 22,1\% (10 orang dari 44 orang anggota DPRD Pol-Man), berarti dapat disimpulkan bahwa intervalnya adalah 7,1\%. Sepintas terjadi peningkatan kuota, namun pada letak sesungguhnya kuota perempuan tetap belum terpenuhi.

Memang angka keterwakilan perempuan di kursi legislatif mengalami peningkatan, namun di Propinsi Sulawesi Barat, khususnya di Kabupaten Polewali Mandar belum dipenuhi angka 30 persen. Sementara masalah- masalah yang berkaitan dengan perempuan masih cukup tinggi. Berdasarkan data BPS di tahun 2012 angka buta huruf di Sulawesi Barat mencapai 12,41 persen dari angka secara nasional sebesar 7,42 persen.. Selain itu berdasarkan data kementerian kesehatan, Angka kematian ibu dan anak di Sulawesi Barat juga masih cukup tinggi.

Sementara di sisi lain, keterwakilan perempuan merupakan tumpuan harapan masyarakat khususnya perempuan untuk memenuhi hak-hak dasar dan azasi sehingga masalah-masalah yang berkaitan dengan kemiskinan dan masalah ketidakadilan gender lainnya dapat diatasi melalui suara perempuan parlemen. Tantangan terhadap keterwakilan perempuan dengan ekspektasi masyarakat yang diidentifikasi dan mendasari dilaksanakannya Penelitian ini dengan melakukan "Survey Harapan Masyarakat terhadap Kinerja Anggota Legislatif Perempuan di Kabupaten Polewali Mandar|". Tujuan Penelitian ini untuk mengetahui;

1. Deskripsi pengetahuan dan pengenalan masyarakat terhadap anggota legislatif perempuan (ALP) terkait Identitasnya, Komisi dan Fraksi/Partainya serta Daerah Pemilihannya (Dapilnya).

2. Harapan masyarakat terhadap peran anggota Legislatif perempuan dalam menjalankan tupoksinya dalam hubungan peningkatan kesejahteraan dan keberpihakan kepada perempuan dan masyarakat miskin ? 


\section{METODE PENELITIAN}

Penelitian dilakukan di tiga wilayah Kecamatan; Polewali, Wonomulyo dan Balanipa.Data yang diambil dalam penelitian ini, bersifat kualitatif. Namun demikian, data kuantitatif tetap diperlukan sejauh mendukung hasil penelitian.

Penelitian ini menggunakan pendekatan kualitatif dengan tipe deskriptif. Lokasi Penelitian dipilih secara purposive. Begitu juga penetuan informan dilakukan secara purposive dengan mempertimbangkan menfokuskan pada perempuan. Mereka yang dipilih adalah orang-orang yang terlibat langsung dalam pengelolaan pembangunan di tingkat desa/kelurahan. Jumlah Informan perdesa 20 orang, terdiri 4 orang Aparat pemerintah desa (1 Kepala Desa, 1 Sekretaris Desa dan 2 anggota BPD dengan memprioritaskan anggota BPD Perempuan), 4 orang perempuan) yang mewakili Pengurus organisasi/lembaga perempuan ditingkat desa/Kelurahan, 12 orang ( 6 laki-laki dan 6 perempuan) dari Informan kunci yang direkrut dari berbagai latar belakang sosial dan organisasi warga setempat, mereka adalah Kader/Perempuan aktifis di tingkat desa/kelurahan; (PKK, Posyiandu, Kelompok Tani dan Nelayan, Kelompok Dasawisma, Kelompok SPP, Guru dan Ormas Perempuan yang ada di tingkat desa/kelurahan.

\section{HASIL DAN PEMBAHASAN}

\section{a. Deskripsi Pengetahuan Umum Responden tentang Anggota Legislatif} Perempuan (ALP)

Data menunjukkan bahwa umumnya responden yang diteliti menyatakan mengenal anggota legislatif perempuan (ALP) yang berasal dari wilayahnya baik di DPRD Tingkat Provinsi dan di DPRD tingkat Kabupaten, walaupun hanya sebahagian kecil menyatakan tidak kenal. Hanya saja mereka tidak bisa menyebutkan semua nama-nama anggota legislatif perempuan tersebut. Baik Responden Aparat Pemerintah Desa maupun Pengurus Organisasi/lembaga perempuan dan Kader/aktifis perempuan ditingkat desa, Pengetahuan mereka tentang ALP cukup baik. Mereka mampu menyebut nama ALP lebih dari 2 orang. Nama-nama yang banyak dikenal antara lain; Dra.Hj.Andi Ruskati Ali Baal, Hj.Marini Ariakati, Hj.Jumiati Mahmud, Hj.Samirah Pratiwi dan Hj.Nurbaeti. 
Tabel 1. Pengetahuan umum Responden tentang Profil Anggota Legislatif Perempuan (APP)

\begin{tabular}{|c|c|c|c|}
\hline Informan & $\begin{array}{c}\text { Kenal Nama } \\
\text { \& Partai } \\
\text { Anggota } \\
\text { Legislatif } \\
\text { Perempuan }\end{array}$ & $\begin{array}{l}\text { Kenal } \\
\text { Komisi \& } \\
\text { Fraksi }\end{array}$ & $\begin{array}{l}\text { Kenal Wilayah } \\
\text { Daerah } \\
\text { Pemilihan } \\
\text { (Dapilnya) }\end{array}$ \\
\hline 1. Aparat Pemerintah desa & 81,67 & 58,33 & 36.67 \\
\hline $\begin{array}{lr}\text { 2. Pengururus } & \text { Organisasi } \\
\text { Perempuan } & \text { ditingkat } \\
\text { desa/kelurahan } & \end{array}$ & 66,67 & 56,67 & 33,33 \\
\hline $\begin{array}{l}\text { 3. Kader/Aktifis Perempuan } \\
\text { desa/lurah }\end{array}$ & 60 & 58,33 & 40 \\
\hline
\end{tabular}

Tabel 1 menjelaskan bahwa kendatipun Aparat Pemerintah Desa, Pengurus Organisasi/lembaga perempuan dan Kader/aktifis Fasilitator Desa mengenal ALP dan Partainya dengan presentase antara 56,67\% - 81,67\% dan, namun ketika ditanyakan Pengetahuan dan pemahaman mereka mengenai Komisi dan Fraksinya serta Wilayah daerah pemilihannya ternyata jawaban warga hanya $33,33-58,33 \%$. Artinya pengetahuan warga terkait hal-hal yang berkaitan wilayah konstituennya relative kurang.Hal ini juga menunjukkan bahwa system relasi atau pola hubungan melalui kunjungan lapangan atau temu konstituen dan diskusi publik kurang tersosialisasikan dari kalangan Anggota DPRD Perempuan,

Pengetahuan Responden tentang ALP pada dapil di wilayahnya tergolong kurang, sebagian besar informan $(>50 \%)$ merasa tidak kenal dengan ALP di dapilnya karena berbagai macam sebab seperti jarang turun ke lapangan, tidak pernah melakukan sosialisasi, atau kunjungan mereka hanya ketika menjelang pemilihan anggota legislatif.

Apakah ALP melakukan temu konstituen baik formal maupun tidak formal, hampir sebagian besar $(66,77 \%$ - 75\%) responden dari Aparat Pemdes, Pengurus organisasi/lembaga perempuan dan Kader/Perempuan aktifis ditingkat desa/kelurahan menyatakan jarang atau kurang memadai. Walaupun ada pula yang menyatakan ada atau cukup ( $25 \%-33,33 \%$ ). 
Tabel 2. Deskripsi Temu Konstituen Anggota Legislatif Perempuan (APP)

\begin{tabular}{|c|c|c|c|}
\hline Informan & $\begin{array}{c}\text { Selalu } \\
\text { (Tinggi) }\end{array}$ & $\begin{array}{c}\text { Cukup } \\
\text { (Sedang) }\end{array}$ & $\begin{array}{c}\text { Kurang } \\
\text { (Rendah) }\end{array}$ \\
\hline 1. Aparat Pemerintah desa & 0 & 33,33 & 66,67 \\
\hline 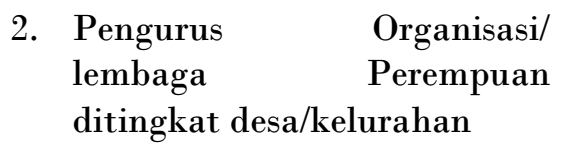 & 0 & 25 & 75 \\
\hline $\begin{array}{l}\text { 3. Kader/ Perempuan Aktifis } \\
\text { desa/lurah }\end{array}$ & 0 & 25 & 75 \\
\hline
\end{tabular}

Ketika responden ditanya, apakah APP yang dikenal masyarakat karena ketokohan atau prestasi. Jawaban dari ketiga elemen Informan tersebut bervariasi seperti: (1) Tanggapan Kader Perempuan/Aktifis desa/lurah dikenal karena sering menghadiri acara adat, karena faktor keluarga/domisili di wilayah tersebut dan mampu bersosialisasi di masyarakat (2) Oleh Pengurus Organisasi/Lembaga Perempuan dikenal karena jabatannya sebagai Pengurus atau Ketua Partai/ormas. (3) Oleh Aparat Pemerintah desa/Lurah dikenal karena ketokohan suami/isteri Gubernur dan isteri Bupati, organisasi keagamaan, menjadi bagian dari beberapa organisasi, karena asal wilayahnya, walaupun ada juga karena prestasi seperti memberi pelayanan yang baik, sering member bantuan sosial.

Jawaban responden tersebut menunjukkan bahwa ALP dikenal masyarakat lebih banyak karena faktor primordial atau ketokohan yang sifatnya mentradisi, bukan karena prestasi yang bersifat fungsional yang dikenang masyarakat. Latar belakang keterpilihan ALP seperti responden di Polewali yaitu: karena kemampuan melakukan sosialisasi dan menjanjikan program tertentu sebelum terpilih, ketokohan dan jalinan kekerabatan, dukungan dari keluarga dan materi. Ada juga karena banyak memberi bantuan social, karena memiliki banyak dana, menjadi orang penting pada ormas keagamaan terbesar di daerahnya, pengaruh keluarga dan juga mungkin partai sedikit, karena beruntung saja, bapaknya rajin turun waktu kampanye, kasih bantuan ke masyarakat, dikenal masyarakat dan diketahui sepak terjangnya. Sedikit berbeda dengan responden Polewaali, maka di Balanipa; walaupun sebahagian menganggap keterpilihan ALP karena dukungan keluarga, atau karena keberuntungan semata tetapi banyak juga responden yang menjawab 
karena lebih mampu membangun komunikasi dengan masyarakat, mampu bersosialisasi, survive dan konsisten dalam berjuang, lebih dipercaya, lebih dekat dengan masyarakat, karena aktivitasnya, sebagai aktivis perempuan dan besar pada partai, memiliki tingkat pendidikan yang tinggi, memiliki keterampilan, punya kapasitas dan aktif pada organisasi. Sifat lain yang menjadi latar belakang keterpilihan ALP seperti: pengaruh partai atau karena efektifnya program pengkaderan partai dianggap kurang.

b. Deskripsi Sosialisasi Program Legislasi yang Berpihak pada Perempuan \& Kemiskinan

Umumnya responden $(66,67$ - $80 \%)$ menyatakan kurang mengenal tentang ada tidaknya produk-produk legislasi/perda yang dihasilkan di DPRD, walupun sisanya ( sekitar $20 \%$ ) menyatakan ada. Namun demikian pengetahuan responden mengenai perda ini masih sangat kurang. Responden sama sekali tidak bisa menyebut Bentuk Perdanya (Nomor dan Tahun) penetapan Perdanya dan secara samar-samar hanya bisa menyatakan ada Perda Perlindungan Anak, Pelayanan Kesehatan, Pendidikan Gratis, Retribusi Pasar dan Terminal.

Tabel 3. Pengetahuan Responden tentang Produk Legislasi (Perda)

\begin{tabular}{|l|l|l|}
\hline \multicolumn{1}{|c|}{ Iforman } & \multicolumn{1}{c|}{$\begin{array}{c}\text { Tidak } \\
\text { Kenal atau } \\
\text { Mengetahui } \\
\text { Kenal/Tidak } \\
\text { mengetahui }\end{array}$} \\
\hline $\begin{array}{l}\text { 1. Aparat Pemerintah Desa } \\
\text { 2. Pengurus Organisasi/ lembaga } \\
\text { Perempuan ditingkat desa/ kelurahan }\end{array}$ & 23,33 & 66,67 \\
$\begin{array}{l}\text { 3. Kader/Aktifis Perempuan di tingkat } \\
\text { desa/kelurahan. }\end{array}$ & 20 & 80,67 \\
\hline
\end{tabular}

Terkait dengan Perda-Perda yang disebutkan responden diatas, kemudian ditanyakan apa kepentingan perempuan tercakup di dalam perda tersebut, sebagian menyatakan kurang tahu karena tidak ada sosialisasi dan sebagian menyatakan kepentingan perempuan sudah tercakup.

Bila ada cakupan produk legislasi itu mengenai perempuan, isinya tentang apa? Responden menjawab Tentang; perlidungan KDRT, 
Perlindungan anak, pelayanan kesehatan gratis, pendidikan gratis, pembinaan dan bantuan modal untuk usaha ibu-ibu rumah tangga.

Ketika ditanyakan mengenai, apakah ada kebijakan atau program mengenai masalah kemiskinan di wilayah anda? Responden umumnya menyatkan ada, seperti : mengenai Raskin, Jamkesmas, Jamkesda, pendidikan gratis, BLT, perbaikan jalan, kesehatan gratis, SPP terkhusus perempuan miskin, perbaikan rumah kumuh, pemberian bantuan melalui PNPM, Program PKH, beras untuk lansia, pembinaan usaha petani rumput laut, pemberian keterampilan bagi perempuan lewat pelatihan, bantuan modal usaha bergulir, pembangunan sarana dan prasaran a, pengadaan tempat usaha kecil. Sebagian respondennya juga mengaku tidak mengetahui/kurang jelas apa Perda itu menekankan prioritas pada kebutuhan warga yang masuk dalam kategori miskin karena tidak pernah mendapat sosialisasi mengenai Perda-Perda di Kabupaten Polman.

c. Harapan Responden Tentang Peran ALP dalam menangani Masalah Perempuan dan Orang Kemiskinan.

Sebenarnya sudah banyak kebijakan atau program mengenai masalah Perempuan dan kemiskinan di Kabupaten Polman, seperti : mengenai Raskin, Jamkesmas, Jamkesda, pendidikan gratis, BLT, perbaikan jalan, kesehatan gratis, Usaha Simpan Pinjam, perbaikan rumah kumuh, pemberian bantuan melalui PNPM, Program PKH, dan lain-lain.Yang perlu diriview dan direflesi untuk diefektifkan adalah pengawalannya agar Perempuan dan Orang Miskin betul-betul sebagai Perencana, Pelaksana dan Penerima Manfaat setiap Program Pembangunan yang ada di desa/kelurahan.

Tabel 4. Haraapan responden terhadap Pengawalan Program yang menjamin keberpuhakan pada Perempuan dan Warga Miskin.

\begin{tabular}{|c|c|c|}
\hline Harapan Responden & $\mathbf{F}$ & $\%$ \\
\hline $\begin{array}{l}\text { 1. ALP harus berperan aktif dalam mensosialisasikan } \\
\text { Program-program pembangunan desa/kelurahan yang } \\
\text { harus dikawal dengan pelibatan Perempuan dan warga } \\
\text { miskin kepada semua stakeholder }\end{array}$ & 60 & 100 \\
\hline $\begin{array}{l}\text { 2. ALP harus mendorong dan menghasilkan } \\
\text { Regulasi/aturan mengenai pengembangan pengkaderan } \\
\text { Aktifis/Kader/Fasilitator Desa. }\end{array}$ & 60 & 100 \\
\hline $\begin{array}{l}\text { 3. ALP juga harus mendorong agar ada Regulasi atau } \\
\text { PERDA yang berkaitan dengan Musrenbang Desa, }\end{array}$ & 60 & 100 \\
\hline
\end{tabular}




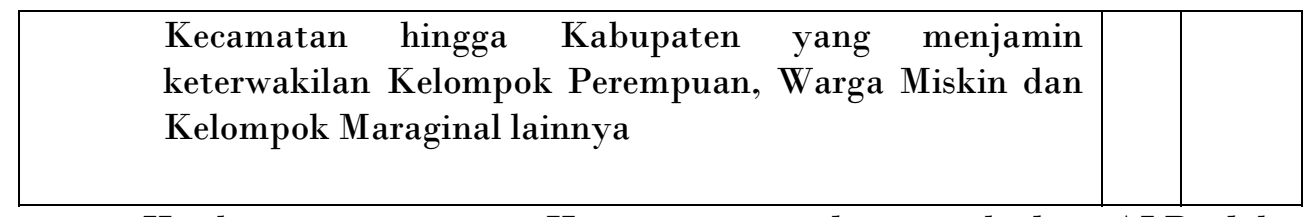

Hasil survey tentang Harapan responden terhadap ALP dalam menangani masalah Perempuan dan Kemiskinan digambarkan sbb; ALP harus berperan aktif dalam mendorong Program-program pembangunan desa/kelurahan yang harus dikawal dengan pelibatan Perempuan dan warga miskin.Sebenarnya skema penganggaran pembangunan desa sudah banyak yang masuk kedesa, hanya yang perlu ditingkatkan dan diefektifkan adalah pengawalannya; yang menjamin agar program-program pembangunan desa/kelurahan betul-betul tepat sasaran, dalam arti Perempuan dan warga miskin dijamin sebagai Perencana Program, Pelaksana Program dan Penerima manfaat Program.

Supaya pengawalan program-program pembangunan desa dapat terwujud, maka ALP harus mendorong dan menghasilkan Regulasi/aturan mengenai pengembangan pengkaderan Aktifis/Kader/Fasilitator Desa. Pendampingan dan pemberdayaan Perempuan dan warga miskin dipedesaan hanya bisa efektif jika tersedia warga setempat yang ada didesa yang berfungsi sebagai Fasilitator Pembangunan. Kader/Aktifis ditingkat Desa/Kelurahan diharapkan memiliki pengetahuan dan keterampilan yang terkait dengan; Gender, Prinsip dan azas-azas pembangunan yang Partisipatif, Transparansi dan Akuntabel. Internalisasi nilai-nilai keberpihakan pada kelompok Perempuan, Miskin dan yang Marginal. Keterampilan; Perencanaan Kelompok, Pendampingan Kelompok dan Monitoring Evaluasi Usaha Kelompok.

Untuk menjamin aspirasi dan kebutuhan Perempuan dan warga miskin terakomodir dan terimplementasikan, maka ALP juga harus mendorong agar ada Regulasi atau PERDA yang berkaitan dengan Musrenbang Desa, Kecamatan hingga Kabupaten, Perda tersebut menjamin adanya keterwakilan Kelompok Perempuan, Warga Miskin dan Kelompok Maraginal lainnya dalam semua prosesnya. Hasil-hasil Musrenbang Desa harus bisa dikawal dijamin usulan-usulan proramnya berkaiaatan kebutuhan Perempuan dan warga miskin. 


\section{SIMPULAN}

Kesimpulan yang dapat diambil dari penelitian ini adalah sebagai berikut:

1. Secara umum pengetahuan masyarakat (Aparat Pemerintah Desa, Pengurus organisasi/lembaga ditingkat desa/kelurahan dan Kader/Aktifis perempuan desa/kelurahan) tentang Profil Anggota Legislatif Perempuan (ALP) di Kabupaten Polman kurang memuaskan. Sebagian besar responden yang diteliti bisa menyebut 2 ALP. Tetapi pengetahuan mereka tentang Profil APP kurang mendalam karena sebahagian besar di antara mereka tidak mengenal dengan baik tentang data lain yang berhubungan dengan APP seperti Jabatan/Komosi dan partainya serta wilayah daerah pemilihan APP itu. Hal ini disebabkan karena ALP jarang bersentuhan langsung dengan masyarakatnya. Saluran atau media yang masyarakat dapat manfaatkan untuk mengenal ALP kurang termanfaatkan.

2. Keterpilihan ALP di setiap wilayah umumnya karena ketokohan orang-orang terdekat dari ALP tersebut seperti ketokohan suami yang pejabat atau hubungan kekeluargaan dari ALP serta kedermawanannya sehingga dapat diartikan bahwa ALP dikenal masyarakat lebih banyak karena faktor primordial, bukan karena prestasi yang bersifat fungsional yang dikenang masyarakat.

3. Produk legislasi seperti Perda yang seharusnya menjadi tupoksi DPRD, kurang atau bahkan tidak dikanl secara memadai oleh masyarakat. Sekitar 66,67 - $80 \%$ responden menyatakan tidak mengetahui bahwa DPRD ada/selalu menghasilkan produk legislasi seperti perda, terutama produk legislasi yang responsif gender dan memiliki keberpihakan terhadap perempuan dan masyarakat miskin . Karena itu, Responden menganggap Anggota Legislatif Perempuan (ALP) dalam menjalankan tupoksinya belum berjalan dengan baik dan masih jauh dari yang diharapkan. ALP di yakini masih belum memperjuangkan program yang responsif gender dan memberdayakan perempuan,.

4. Kebijakan program masalah kemiskinan (termasuk Perempuan) di Kabupaten Polman menurut pengakuan sebahagian besar responden sudah mulai banyak dilakukan pemerintah. Yang perlu diperhatikan untuk diriview dan direflesi adalah system pengawalannya agar Perempuan dan Orang Miskin betul-betul sebagai Perencana, Pelaksana dan Penerima Manfaat dari setiap program pembangunan yang ada di desa/kelurahan.

5. Harapan Masyarakat terhadap Pengawalan Program Pembangunan yang responsive gender dan menjamin keberpihakan pada Perempuan dan Warga 
Miskin adalah; ALP harus berperan aktif dalam mensosialisasikan Programprogram pembangunan desa/kelurahan yang harus dikawal dengan pelibatan Perempuan dan warga miskin kepada semua stakeholder, ALP harus mendorong dan menghasilkan Regulasi/aturan mengenai pengembangan penguatan SDM Aktifis/Kader/Fasilitator Desa Perempuan. ALP juga harus mendorong agar ada Regulasi atau PERDA yang berkaitan dengan Musrenbang Desa, Kecamatan hingga Kabupaten yang menjamin keterwakilan Kelompok Perempuan, Warga Miskin dan Kelompok Maraginal lainnya

\section{SARAN DAN REKOMENDASI}

Berdasarkan hasil pembahasan dan simpulan tersebut, peneliti memberikan saran sebagai berikut:

1. Perlunya pembekalan dan penyadaran kepada ALP tentang Pembangunan yang responsive Gender Poverty Inclusif (GPI)

2. Meningkatkan aktifitas ALP tentang produk legislasi yang berkenaan dengan perempuan dan kemiskinan.

3. Peningkatkan jalinan komunikasi ALP dan Masyarakat melalui programprogram yang partisipatif dan responsive Gender Poverty Inclusif.

4. Hasil penelitian ini dapat dijadikan sebagai dasar untuk menetapkan kebutuhan dan kegiatan peningkatan kapasitas perempuan parlemen khususnya di Kabupaten Polman dan daerah-daerah lainnya di Provinsi Sulawesi Barat.

\section{DAFTAR PUSTAKA}

Alamsyah A.R. dan M.A.Muslim. 2006. Model Penilaian Kinerja Wakil Rakyat: Panduan untun menilai Kinerja Anggota DPR/DPRD. Departemen Ilmu Administrasi Fakultas Ilmu Sosial dan Ilmu Politik Universitas Indonesia. Depok.

BPS Kabupaten Polman. 2016. Kabupaten Polman dalam Angka Tahun 2015. Badan Pusat Statistik Kabupaten Polman

Djoyosoekarto, A. 2004. Dinamika dan Kapasitas DPRD dalam Tata Pemerintahan Demokratis. 
Kalyanamitra. 2011. Menelisik Partisipasi Perempuan dalam Musrenbang: Kajian terhadap Kebijakan-Kebijakan Terkait. Kerjasama Program RHV-Oxfarm GB dengan Kalyanamitra. Jakarta.

Kartiwa, H.A. Implementasi Peran dan Fungsi DPRD dalam Rangka Mewujudkan "Good Governance". 